\title{
COST-EFFECTIVE HIGH-FIELD MAGNETS FOR FUTURE ACCELERATORS
}

\author{
R. B. Meinke, M. J. Ball, C. L. Goodzeit, Advanced Magnet Laboratory, Palm Bay, FL, USA
}

\section{Abstract}

We describe a modification of the traditional $\cos \theta$ accelerator magnet design that substantially reduces the cost of manufacture of accelerator magnets. Instead of the Rutherford type cable, a round multi-strand cable is used. This cable is placed in precisely formed grooves in cylindrical surfaces or flat plates that are then nested together to form the coil assembly. Cost reductions are achieved by the elimination of expensive coil end parts, coil wedges and spacers, collars, and coil molding equipment. Also, conductor stress management is obtained by having each conductor supported in its own groove and thus there is no need for application of azimuthal pre-stress to the coil. Thus, coil sizing measurements and collaring press operations are eliminated. We describe an example design for such a magnet to operate at $6.6 \mathrm{~T}$ and show a performance and cost comparison to the $6.6 \mathrm{~T}$ dipole that was developed for use in the SSC.

\section{INTRODUCTION}

The use of a round superconducting cable for high field magnets, rather than the flat Rutherford style cable, has certain advantages that enable a reduction in the cost of manufacture and assembly of such magnets. In addition to the saving in the cost of parts, tooling, and assembly, the round cable does not experience degradation in the cabling process and is less costly to produce than the flat cable.

An example is given of a round cable magnet design that has characteristics comparable to the SSC dipole magnet. The SSC dipole was designed to produce a field of $6.6 \mathrm{~T}$ in a $50 \mathrm{~mm}$ coil aperture in magnets that were typically $15 \mathrm{~m}$ long. We will compare this SSC magnet, for which performance and cost information is well documented, with an equivalent design in which the collared coil assembly is replaced with the round cable coil assembly, while the remainder of the cold mass remains essentially the same.

\section{THE ROUND CABLE MAGNET DESIGN}

In the design of a round cable dipole magnet coil, the coil layers are made from a round multi-strand cable that is placed in U-shaped grooves on cylindrical surfaces. A schematic cross section for the conductor arrangement of such a coil is shown in Fig. 1. For comparison, a cross section of the SSC magnet that used Rutherford style cable is shown in Fig. 2.

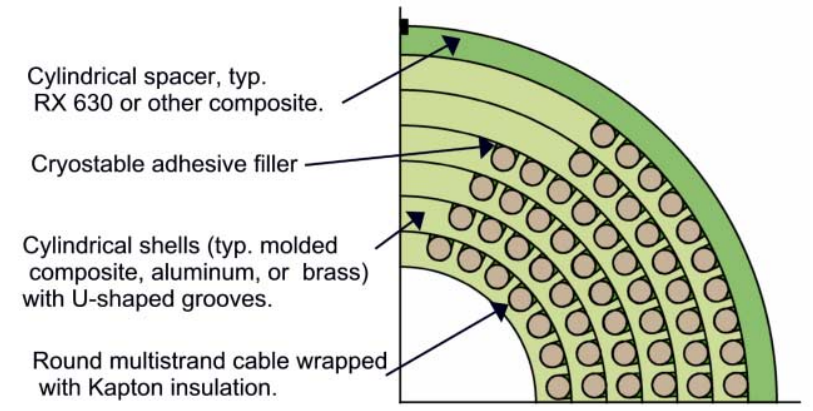

Fig 1. Round cable magnet coil section

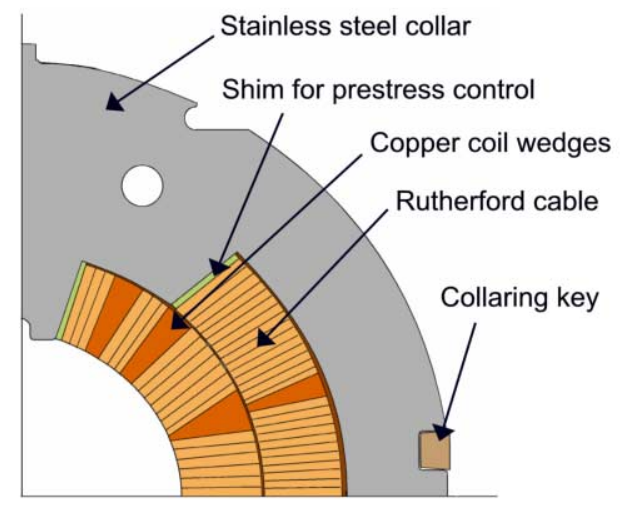

Fig 2. SSC dipole coil section

\section{PERFORMANCE COMPARISON - SSC DIPOLE}

A cross section of an SSC prototype dipole is shown in Fig. 3. The magnetic design and performance of this magnet is well documented. The collared coil assembly of the SSC dipole can be replaced with a round cable coil assembly as shown in Fig. 4. In this case we can compare the performance of the two magnet configurations.

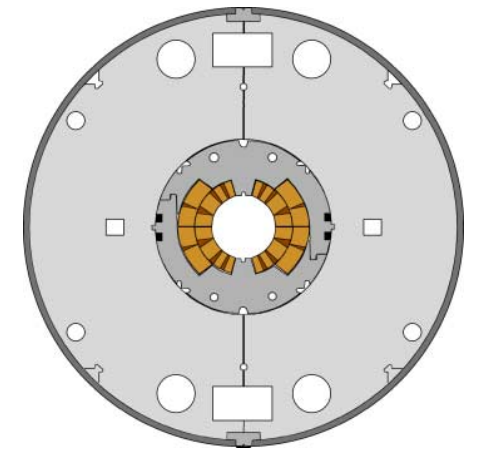

Fig. 3. SSC

Prototype Dipole

(FNAL Version) 


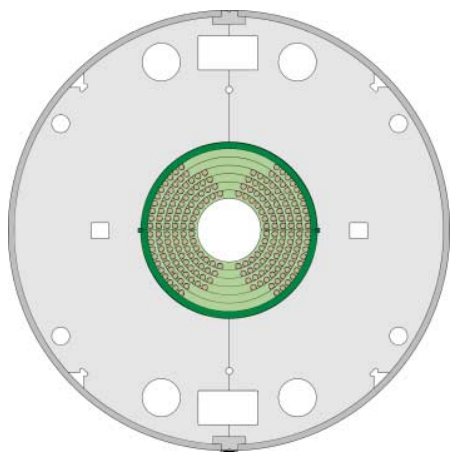

Fig. 4. Round cable coil assembly in same cold mass as SSC prototype dipole

Table 1. Basic Parameters for the SSC Dipole and the Comparable Round Cable Magnet Design

\begin{tabular}{|l|l|l|}
\cline { 2 - 3 } \multicolumn{1}{c|}{} & $\begin{array}{l}\text { Round Cable } \\
\text { Magnet }\end{array}$ & SSC Dipole \\
\hline Central field, $\mathrm{T}$ & 6.6 & 6.6 \\
\hline $\begin{array}{l}\text { Operating current, } \mathrm{A} \\
\text { (inner/outer) }\end{array}$ & $5200 / 7500$ & 6503 \\
\hline Magnetic length, $\mathrm{m}$ & 15.165 & 15.165 \\
\hline Stored energy, $\mathrm{MJ}$ & 1.58 & 1.58 \\
\hline Inductance, $\mathrm{mH}$ & 83 & 75 \\
\hline Operating temp, $\mathrm{K}$ & 4.35 & 4.35 \\
\hline Yoke inner radius, $\mathrm{mm}$ & 67.8 & 67.8 \\
\hline Yoke outer radius, $\mathrm{mm}$ & 165 & 165 \\
\hline $\begin{array}{l}\text { Total weight of SC } \\
\text { cable, } \mathrm{sg}\end{array}$ & 530.3 & 618 \\
\hline Total cable length, $\mathrm{m}$ & 3392 & 2886.8 \\
\hline Number of coil wedges & 0 & 4 \\
\hline
\end{tabular}

The basic parameters for the two magnet design types are summarized in Table 1. The example round cable magnet uses a 6-layer coil (as shown in Fig. 1), in which the four inner layers have a cable strand with a $1.3: 1$

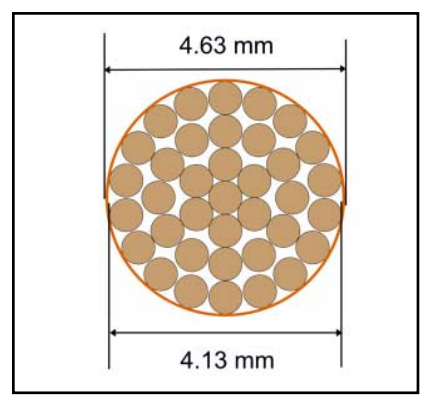

Fig. 5. Configuration of 37 strand cable

$\mathrm{Cu}: \mathrm{SC}$ and the outer two layers use a $1.8: 1 \mathrm{Cu}: \mathrm{SC}$ cable strand. The cable magnet uses a Kapton wrapped 37strand cable as shown in Fig. 5. The required central field $(6.6 \mathrm{~T})$ is obtained when the inner layers are operated at $5200 \mathrm{~A}$ and the outer two layers at $7500 \mathrm{~A}$.

A magnetic field plot for this case is shown in Fig. 6. In this example the same sized conductor is used for both the inner and outer layers and some optimization in the use of superconductor is obtained by adjusting the $\mathrm{Cu}$ :SC .
Fig. 6. Field plot for example cable magnet with 53 turns, $5200 \mathrm{~A}$ in the inner 4 layers and $7500 \mathrm{~A}$ in the outer 2 layers. Peak field values for computing the margin are shown for the inner and outer layers. In this example the operating current margin is $17 \%$ for the inner layers and $30 \%$ for the outer layers.

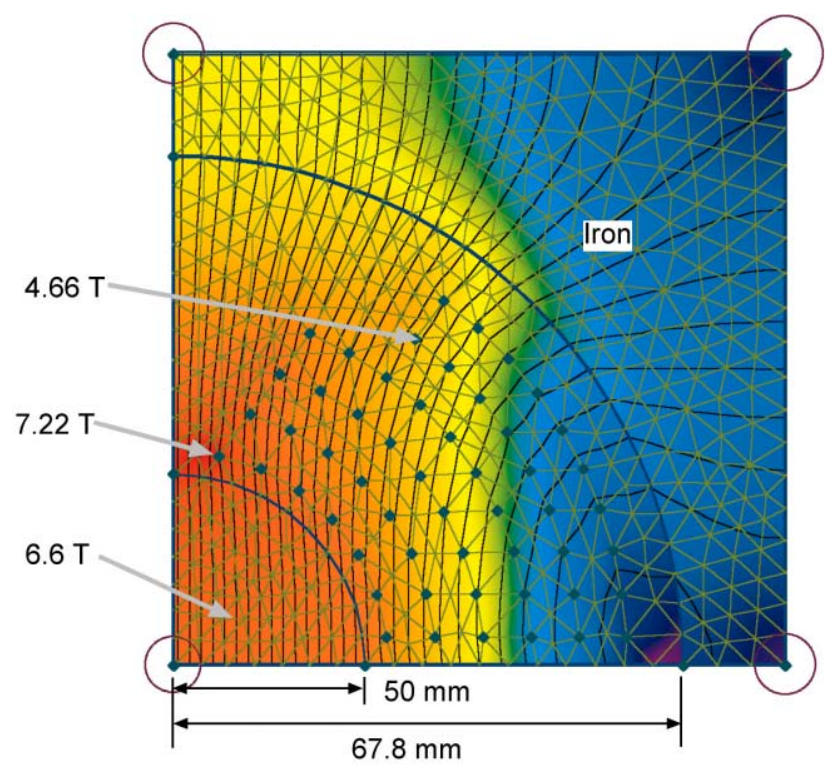

4 MAGNET COST CONSIDERATIONS

Since cost is such an important consideration in any project involving the production of a number of superconducting accelerator magnets, the use of the round cable coil design instead of coils using the flat Rutherford style cable is clearly indicated. The cost savings are apparent in both the tooling and magnet material costs in the $R \& D$ or magnet development phase as well as in the production of the magnet series.

\subsection{Tooling costs}

In the case of a magnet such as the SSC dipole or other type of flat cable magnet, expensive tooling is needed, even for the production of the first prototype or $R \& D$ version. Table 2 shows examples of major tooling required for the SSC dipole that would not be needed for the round cable magnet. The costs were obtained from the SSC baseline cost estimate reported as of 9/15/93.

Table 2. Major tooling for SSC dipole coils - not required for round cable magnet coils

\begin{tabular}{|l|l|}
\hline Coil winding mandrels (inner \& outer coils) & $\$ 192,078$ \\
\hline Coil curing machine & $\$ 448,273$ \\
\hline Coil curing form blocks & $\$ 841,000$ \\
\hline Heater-cooler & $\$ 46,000$ \\
\hline Azimuthal coil size tooling & $\$ 22,923$ \\
\hline Collaring press & $\$ 574,841$ \\
\hline Collaring fixture (form block) & $\$ 410,000$ \\
\hline Total & $\$ 2,535,115$ \\
\hline
\end{tabular}


The cost of the coil-winding machine is not included above since a similar machine would be required to wind the coils for the round cable magnet. However, the expensive winding mandrels are not needed and thus they are listed in the above table. The reduction in tooling requirements represents a significant advantage of the round cable magnet design.

\subsection{Coil component costs}

The primary driver for the cost saving is the elimination of the requirement to assemble the magnet coils with a high azimuthal pre-stress that was required for the Rutherford cable magnet.

Since each turn in the round cable magnet is supported in its own groove, it is not necessary to apply azimuthal pre-stress to the coil and thus coil assembly is simplified. High strength stainless steel (or aluminum) collars are eliminated since there is no need to compress the coils. Collaring presses and coil sizing operations to ensure proper pre-stress for the coil geometry are eliminated. No pre-stress measurement technology or equipment is required.

Since the round cable is placed in precisely-located grooves on cylindrical shells, the coil winding is simplified. The need for precision (constant perimeter bend) end pieces and spacer pieces for coil ends is eliminated. Also, precision copper wedges between the coil blocks are not required, nor are pole shims needed to adjust pre-stress. The use of specially formed Kapton insulation layers to insulate the coil is not required.

For the production of many magnets of this type, the cylindrical shells on which the superconductor is placed can be mass-produced by injection molding similar to the way that the coil insulators were made for the RHIC magnets. The cost estimate for these parts was obtained from a potential vendor [1].

Table 3 shows the costs for the principal coil assembly components for a $15 \mathrm{~m}$ long dipole magnet for each of the two magnet design types. The superconductor is assumed to cost about the same for each magnet type.

Table 3. Cost of Components

\begin{tabular}{|l|l|l|}
\hline Component & $\begin{array}{l}\text { Round } \\
\text { Cable } \\
\text { Magnet }\end{array}$ & $\begin{array}{l}\text { SSC Dipole } \\
(8-12)\end{array}$ \\
\hline Coil end parts & $\$ 0$ & $\$ 5,089$ \\
\hline Kapton insulation \& Shims & $\$ 0$ & $\$ 1,154$ \\
\hline Collar lamination assemblies & $\$ 0$ & $\$ 7,456$ \\
\hline Coil wedges & $\$ 0$ & $\$ 4,747$ \\
\hline Cylindrical coil shells (straight sections) & $\$ 9,600$ & $\$ 0$ \\
\hline Cylindrical coil shells (ends) & $\$ 2,400$ & $\$ 0$ \\
\hline Coil insulator-spacer & $\$ 1,300$ & $\$ 0$ \\
\hline Totals & $\$ 13,300$ & $\$ 18,446$ \\
\hline
\end{tabular}

\subsection{Labor costs}

Labor cost estimates associated with making the coil assembly for a $16 \mathrm{~m}$ long SSC dipole magnet were reported in the SSC baseline cost estimate. The labor hours shown in Table 4 were estimated for the four coil sections that make up a complete $15 \mathrm{~m}$ long SSC dipole coil assembly. These labor costs would not be required for the round cable magnet in the example. However, assembling the cylindrical coil shells for the round cable magnet could require 16 man hours per unit, similar to the effort to install collar packs on the SSC coils. Other labor costs, such as coil winding, that are common to both of the magnet types are not shown. Thus, the net labor saving for the round cable magnet is estimated at 112 man-hours/magnet

Table 4. Labor estimates in man-hours (MH) for SSC dipole coils - not required for round cable magnet coils.

\begin{tabular}{|l|l|l|l|}
\hline & Units & MH/unit & total \\
\hline Wedge wrapping & 4 & 4 & 16 \\
\hline Winding mandrel prep & 4 & 6 & 24 \\
\hline Coil curing prep & 4 & 2 & 8 \\
\hline Coil curing & 4 & 4 & 16 \\
\hline Coil extraction & 4 & 2 & 8 \\
\hline Coil measurements-azimuthal & 4 & 2 & 8 \\
\hline Coil measurements-length & 4 & 0.2 & 0.8 \\
\hline Install Kapton insulation & 1 & 10 & 10 \\
\hline Collar pack shim installation & 1 & 16 & 16 \\
\hline $\begin{array}{l}\text { Collar pack install on coils [See } \\
\text { note] }\end{array}$ & 1 & 16 & 16 \\
\hline Collar press \& key & 1 & 4 & 4 \\
\hline Post collaring measurements & 1 & 2 & 2 \\
\hline $\begin{array}{l}\text { Total man-hours required for } \\
\text { these operations }\end{array}$ & & 128.8 \\
\hline
\end{tabular}

\section{SUMMARY AND CONCLUSIONS}

This study has shown that the use of a round cable rather than the flat Rutherford style cable in accelerator magnet coils can result in significant cost savings for the project. Furthermore, the round cable coil design can be advantageous for prototype or small production run magnets since it does not require expensive tooling such as coil molding tooling and coil-winding mandrels. It has been shown that the round cable magnet design embodies a simplified coil assembly, which requires fewer components and costs significantly less than the coil assembly for a flat cable magnet of similar performance. Furthermore, the elimination of the requirement to apply azimuthal pre-stress to the coil has also resulted in a significant labor saving in the fabrication and assembly operations for the coil package.

\section{REFERENCES}

[1] Communication from John A. Bishop, Jr., Engineering Manager, Wiggins Plastics, Inc., 6/01/01. 